\title{
Vaccination in the prevention of infectious respiratory diseases in adults
}

\author{
Brazilian Society of Pneumology and Tisiology \\ Final Elaboration: December $21^{\text {st }}, 2012$ \\ Participants: Fernando Lundgren, Bernardo Maranhão, Ricardo Martins, José Miguel Chatkin, Marcelo Fouad Rabahi MF, Ricardo Amorim \\ Corrêa, Mara Rúbia F. de Figueiredo, Nathalia Carvalho Andrada, Roberto Stirbulov
}

http://dx.doi.org/10.1590/1806-9282.60.02.004

\section{DESCRIPTION OF THE EVIDENCE COLLECTION METHOD:}

Active searches were made on the Pubmed/MEDLINE, Scielo/LILACS and Cochrane Library databases, using the following descriptive terms (MeSH terms): Vaccines, Vaccination, Immunization, Immunization Schedule*, Immunization Programs, Mass vaccination, Vaccines, Inactivated; Vaccines Attenuated, Vaccines, Synthetic; Antiviral Agents, Antibodies, Viral; Virus Shedding*, Disease Notification, Disease Outbreaks, Influenza Vaccines, Influenza A Virus, Influenza, Human/prevention \& control, Bacterial Vaccines, Vaccines, Acellular; Antibodies, Bacterial; Diphtheria Vaccine, Pertussis Vaccine, Bordetella pertussis*, Diphtheria/prevention o control; Whooping Cough; Vaccines, Combined; DTPP vaccine, Diphtheria-Tetanus-Pertussis Vaccine, Diphteria Tetanus acellular Pertussis Vaccines, Tetanus, Poliovirus Vaccine, Inactivated; BCG Vaccine, TuberculinTest, Tuberculosis, Pulmonary/prevention o control, Tuberculosis, Tuberculosis,Pul monary; Pneumococcal Vaccines, Streptococcal Vaccines, Pneumococcal Infection/prevention es control, 23-valente pneumococcal capsular polysaccharide vaccine, heptavalent pneumococcal conjugate vaccine, Splenectomy, Diabetes Mellitus, Diabetes Complications, Anemia, Sickle Cell, Hemoglobinopathies, Pulmonary Disease, Chronic Obstructive; HIV Infections, HIV Seropositivity, AIDS, Acquired Immunodeficiency Syndrome, Cerebrospinal Fluid Rhinorrhea, cerebrospinal fluid leak (CSF), Smoking, Alcohol-Related Disorders, Alcoholism, complications, bacteremia, Liver Cirrhosis, Alcoholic, Immunosuppression, Dose-Response Relationship, Immunologic, Immunizations Programs, Immunization, Secondary; Patient Participation, Dose-Response Relationship, Immunologic; Risk, administration \& dosage*; adverse effects*, mortality, Cost-Benefit Analysis, Injections, Intramuscular; Injections, Intradermal; administration, intranasal; utilization, prevention o control; Immunity, Maternally-Acquired; Pregnancy, Pregnancy Complications, Infectious.

\section{Level of recommentadion and strength of evidence:}

A: Experimental or observational studies with better consistency.

B: Experimental or observational studies with lower consistency.

C: Case reports (uncontrolled studies).

D: Opinion without critical evaluation, based on consensus, physiological studies or animal models.

\section{Objective}

To present alternatives to existing vaccines for the prevention of infectious respiratory diseases in adults, with their recommendations, adverse effects and contraindications.

\section{Conflict of interest}

The conflicts of interest declared by the participants in the elaboration of these guidelines are detailed on page 12.

\section{INTRODUCTION}

Despite the large advancements in Public Health resulting from immunization, there are still deaths or illness caused by diseases that could be prevented using vaccines.

Vaccination, initially focused exclusively on the child and adolescent range, was extended to all ages. The adult and elderly immunization schedule of the National Adult and Elderly Vaccination Program from the Ministry of Health (MH) is presented below (Table 1), and includes some of the vaccines, such as hepatitis and yellow fever immunization, since the focus is on the prevention of respiratory diseases in adults and the elderly. 
TABLE 1 Vaccination calendar for adults and the elderly

\begin{tabular}{|c|c|c|c|}
\hline Age & Vaccine & Dose & Diseases avoided \\
\hline \multirow{4}{*}{$\begin{array}{l}20 \text { to } 59 \\
\text { years }\end{array}$} & $\begin{array}{l}\text { Hepatitis B }{ }^{(1)} \text { (vulnerable groups) } \\
\text { Hepatitis B vaccine (recombinant) }\end{array}$ & Three doses & Hepatitis B \\
\hline & $\begin{array}{l}\text { Double, adult type }(\mathbf{d T})^{(2)} \\
\text { Adult diphtheria and tetanus vaccine }\end{array}$ & One dose every ten years & Diphtheria and tetanus \\
\hline & $\begin{array}{l}\text { Yellow fever }{ }^{(3)} \\
\text { Yellow fever vaccine (attenuated) }\end{array}$ & One dose every ten years & Yellow fever \\
\hline & $\begin{array}{l}\text { Triple vaccine }(M M R)^{(4)} \\
\text { Measles, mumps and rubella vaccine }\end{array}$ & Single dose & Measles, mumps and rubella \\
\hline \multirow{5}{*}{$\begin{array}{l}60 \text { years } \\
\text { or more }\end{array}$} & $\begin{array}{l}\text { Hepatitis B }{ }^{(1)} \text { (vulnerable groups) } \\
\text { Hepatitis B vaccine (recombinant) }\end{array}$ & Three doses & Hepatitis B \\
\hline & $\begin{array}{l}\text { Yellow fever }{ }^{(3)} \\
\text { Yellow fever vaccine (attenuated) }\end{array}$ & One dose every ten years & Yellow fever \\
\hline & $\begin{array}{l}\text { Seasonal influenza } \\
\text { Influenza vaccine (fractional inactivated) }\end{array}$ & Annual dose & Seasonal influenza \\
\hline & $\begin{array}{l}\text { 23-valent pneumococcal }(\mathbf{P n} 23)^{(6)} \\
23 \text {-valent pneumococcal vaccine (polysaccharide) }\end{array}$ & Single dose & Infections caused by Pneumococcus \\
\hline & $\begin{array}{l}\text { Double, adult type }(\mathbf{d T})^{(2)} \\
\text { Adult diphtheria and tetanus vaccine }\end{array}$ & One dose every ten years & Diphtheria and tetanus \\
\hline
\end{tabular}

ADULT AND ELDERLY VACCINATION CALENDAR, ${ }^{2}(\mathbf{D})$.

Note: Maintained the nomenclature of the National Immunization Program and inserted the nomenclature according to the Collegiate Directorship Resolution- RDC $\mathrm{n}$. 61 , August 25 2008 Brazilian Sanitary Surveillance Agency (ANVISA).

The vaccines used in adults for the prevention of infectious diseases include four diseases with a high level of invasiveness and morbidity, which contribute to increasing mortality in our patients.

1 - Vaccine against the influenza virus

2 - Vaccine against pertussis

3 - Vaccine against tuberculosis

4 - Vaccine against Streptococcus pneumoniae

\section{IS THERE A BENEFIT TO THE USE OF FLU VACCINES?}

Flu symptoms are mostly caused by the influenza virus, notably types A and B, the latter on a lower scale.

The high rate of mutation of the virus' antigenic structure contributes to increasing the annual incidence of the disease at determined times of the year, and justifies the need for annual vaccination, since the protection given by the flu vaccine is temporary ${ }^{3}(\mathbf{B})$. Cases of flu used to occur at cold times of the year. In the north region of Brazil, they occur mostly in the rainy period, which coincides with the winter in the Northern Hemisphere (December to February). In the other regions of the country, the peak incidence occurs between May and August. This variability continually challenges the immunological system to carry out its defensive role against the aggression of new variants of the virus circulating in the community. The incidence of hospitalization owing to complications resulting from influenza is 0.8 (CI 95\% 0.1-1.15) per 1000 people/year in the age range $18-49$ years, and 1.06 (CI 95\% 7.5-13.6) per 1000 people/year in patients over 65 years $^{3}(\mathbf{B})$.

Aware of this information, specialists coordinated by the US Centers for Disease Control (CDC) and the World Health Organization (WHO) met to decide, based on data derived from sentinel laboratories spread all over the world, on the composition of the flu vaccine to be given from May to October in the Southern Hemisphere and from November to April in the Northern Hemisphere ${ }^{1.46}(\mathbf{D})$.

The vaccine used in Brazil is the trivalent type, with inactivated fragmented viral particles ${ }^{7}(\mathbf{D})$, with a recommended adult dose of $0.5 \mathrm{~mL}$ intramuscularly in the deltoid region.

Inactive seasonal flu vaccines have been used since $1940^{8}$ (D). The vaccine is inactivated using formaldehyde, uses thimerosal as a preservative and is produced by viral growth in embryonated chicken eggs. Given the greater power of mutation of type $A$, the composition of the vaccine normally contains two antigenic variants of type $A$ and one variant of type $B$. There is a benefit to the use of inactivated trivalent vaccine in relation to the attenuated vaccine. The inactivated form leads to a higher num- 
ber of serum antibodies and there is a tendency for a lower number of vaccine reactions ( $0.5 \%$ versus $0.8 \%$ ), but with no significant differences. Patients immunized with inactivated vaccine that subsequently develop flu symptoms have lower fever intensity ${ }^{9}(\mathbf{B})$.

The vaccine is formally contraindicated for individuals allergic to eggs or egg derivatives or who have presented allergies to previous doses. For patients with previous diagnosis of Guillain-Barré syndrome, the use of the vaccine should be studied carefully ${ }^{8}(\mathbf{D})$. There is also voluntary refusal of the vaccine, even in patients considered as high $\operatorname{risk}^{10}(\mathbf{B})$.

In general, the use of inactivated vaccine is well tolerated, few collateral effects being described. Pain in the vaccination site is the most frequent adverse effect, potentially reaching $46 \%$ of injections. Low intensity fever and light systemic symptoms such as fatigue (24\%), headache (19\%) and myalgia (18\%) may occur 8 to 24 hours after immunization ${ }^{11}(\mathbf{A})$.

The medical literature has demonstrated that the systematic use of flu vaccines does not decrease the prevalence of the clinical symptoms of $\mathrm{flu}^{12.13}(\mathbf{D})$, however it causes a significant reduction in cases of pneumonia, hospital admissions and death caused by the illness. There is a fall of $27 \%{ }^{14}(\mathbf{B})$ to $32 \%{ }^{15}(\mathbf{B})$ in the number of hospitalizations for pneumonia or flu, and a reduction of $37 \%{ }^{16}(\mathbf{B}), 45 \%{ }^{15}(\mathbf{B})$, $48 \% \%^{14.17}(\mathbf{B})$, and even $50 \%^{17}(\mathbf{B})$ in the risk of death for all causes in the winter14(B). It also reduces the number of office visits (17\% for pneumonia or flu and $6.4 \%$ for visits due to any respiratory condition) as well as reducing the cost of hospitalization by $30.7 \%{ }^{15}(\mathbf{B})$. Flu vaccines reduce the risk of hospitalization for cardiac diseases by $19 \%(\mathrm{p}<0.001)$, and between 16 and $23 \%$ for cerebrovascular diseases $(p<0.018 \text { and } p<0.001 \text {, respectively })^{17.18}(\mathbf{B})$, as well as reducing mortality for cardiac causes in $37 \%$ of the cases ${ }^{16.18}(\mathbf{B})$.

In principle, any person over 6 months of age can use the vaccine annually; however, in general, on account of limited stocks, it is recommended for the vaccine to be administered preferably to the following groups of people ${ }^{7}(\mathbf{D})$ :

1. Individuals over 50 years;

2. Residents of orphanages or nursing homes;

3. Patients that present chronic cardiovascular or pulmonary diseases, including asthma;

4. Patients with chronic metabolic diseases, such as diabetes mellitus, hepatic, renal and hematological diseases;

5. Patients with immunosuppression;
6. Patients with neurological or neuromuscular diseases that could compromise their pulmonary defenses;

7. Pregnant women or those of fertile age;

8. Workers in the healthcare area;

9. Individuals of indigenous ethnicity;

10. Individuals with obesity at advanced levels;

11. Children aged from 6 months to 5 years.

\section{Recommendation}

The flu vaccine available in Brazil is the trivalent type with fragmented and inactivated viral particles, whose application should be done intramuscularly and annually. The use of the flu vaccine is indicated for special groups of adults $^{1.4-7}(\mathbf{D})$. The vaccine does not reduce the clinical symptoms of the illness, but enables significant reductions in pneumonias, hospital admissions and death caused by $\mathrm{flu}^{14}(\mathbf{B})^{12.13}(\mathbf{D})$. It is formally contraindicated in individuals allergic to eggs or egg derivatives and to those who have displayed allergies in previous $\operatorname{doses}^{8}(\mathbf{D})$.

\section{IS THERE BENEFIT TO THE USE OF PERTUSSIS VACCINES?}

There are three vaccines against whooping cough for adults licensed in Brazil ${ }^{19-21}$ (D). These vaccines are only available in private services ${ }^{22}(\mathbf{D})$.

The first vaccine, licensed in 2001, is composed of a combination of three components against diphtheria, tetanus and acellular pertussis $(\mathrm{dTpa})^{19}(\mathbf{D})$. The other two vaccines were licensed in Brazil in 2011 but being used at a global level since $2005^{20.21}$ (D). Both combine components against diphtheria, tetanus, acellular pertussis and inactivated poliomyelitis (dTpa-IPV) ${ }^{20.21}(\mathbf{D})$.

TABLE 2 The antigen compositions in the vaccines ${ }^{19-21}(\mathrm{D})^{23}(\mathrm{~B})$

\begin{tabular}{|c|c|c|c|}
\hline & $\mathrm{dTpa}^{19}(\mathrm{D})$ & dTpa-IPV ${ }^{21}(\mathrm{D})$ & dTpa-IPV ${ }^{20}(D)$ \\
\hline \multicolumn{4}{|l|}{ Antigens } \\
\hline PT $(\mu \mathrm{g})$ & 8 & 8 & 2,5 \\
\hline $\operatorname{HAF}(\mu \mathrm{g})$ & 8 & 8 & 5 \\
\hline PRN $(\mu g)$ & 2,5 & 2,5 & 3 \\
\hline FIM $2+3(\mu \mathrm{g})$ & - & - & 5 \\
\hline$D(L f)$ & 2,5 & $2(\geq 2 \mathrm{UI})$ & $2(\geq 2 \mathrm{UI})$ \\
\hline $\mathrm{T}(\mathrm{Lf})$ & 5 & $5(\geq 20 \mathrm{UI})$ & $5(\geq 20 \mathrm{UI})$ \\
\hline \multicolumn{4}{|l|}{ Pólio (D-Ag-U) } \\
\hline 1 & - & $40 \mathrm{D}$ & $40 \mathrm{D}$ \\
\hline 2 & - & $8 \mathrm{D}$ & $8 \mathrm{D}$ \\
\hline 3 & - & $32 \mathrm{D}$ & $32 \mathrm{D}$ \\
\hline
\end{tabular}

$\mathrm{D}=$ diphtheria toxoid; FIM $2+3$ = fimbriae 2 and 3 ; = FHA Filamentous haemagglutinin; $\mathrm{Lf}=$ flocculation poliovirus vaccine limits; Polio $=1,2$ and 3 polio vaccination; PRN = Pertactin, PT $=$ pertussis toxin; $T=$ Tetanus toxoid . 
All of the vaccines have aluminum phosphate adjuvant and 2-phenoxyethanol and polysorbate 80 excipients. The vaccines may contain traces of neomycin, streptomycin, polymyxin B, glutaraldehyde and formaldehyde ${ }^{19-21}(\mathbf{D})$. They are presented in the form of a suspension, in single dose syringes of $0.5 \mathrm{~mL}$, ready to use $\mathrm{e}^{19-21}(\mathbf{D})$.

It is recommended for booster vaccination against diphtheria, tetanus and whooping cough ${ }^{19-21}(\mathbf{D})$, as between the decades of 1970 and 1980 there were resurgences of whooping cough in various parts of the world ${ }^{24}(\mathbf{B})$, resulting from the low presence of antibodies for these diseases in individuals over 40 years, even in patients that completed the full basic vaccination scheme $e^{25}(\mathbf{B})$. Brazil, like the whole of Latin America, has maintained the certificate granted by the WHO for eradication of the poliomyelitis virus ${ }^{1.6}(\mathbf{D})$.

Administration should be intramuscular, preferably in the deltoid muscle, and may be applied from the age of 11 years, that is, the vaccine may be given to adolescents, adults and the elderly ${ }^{19-22}$ (D).

The recommended vaccination schedule depends on three situations of the vaccine status.

$1^{\circ}$ If the basic vaccination scheme is complete - substitute the booster dose of $\mathrm{dT}$ with $\mathrm{dT}$ pa or dTpa-IPV. If the individual has already received the booster dose with adult diphtheria or tetanus or adult double bacteria $(\mathrm{dT})$, there is no need for an interval of the dose with dTpa or dTpa-IPV as a booster for the diseases not covered in the $\mathrm{dT}^{26}(\mathbf{D})$;

$2^{\circ}$ If the basic vaccination scheme is incomplete (one or two doses of the tetanic component received over the lifespan) - complete the scheme of 3 doses by applying:

- One dose of dTpa or dTpa-IPV if there are two previous doses of the tetanic component ${ }^{22}(\mathbf{D})$;

- One dose of dTpa or dTpa-IPV and, after a minimum interval of 2 months, another dose of dT, if a previous dose of the tetanic component was received $^{22}(\mathbf{D})$.

$3^{\circ}$ If the vaccination scheme has not been carried out or is unknown - proceed with vaccination at an interval of 0,2 , and 6 months. With the first dose of dTpa or dTpa-IPV and subsequent doses with $\mathrm{dT}^{22}(\mathbf{D})$.

In special situations, the interval between the 1 st and 2 nd doses may be reduced to 1 month, between the 2 nd and 3 rd doses, maintain the interval of 6 to 12 months $^{27}(\mathbf{D})$.

The vaccination against whooping cough is especially recommended in adults that live with or care for infants aged less than one year, given they are the main transmitters of Bordetella pertussis to this group ${ }^{22}(\mathbf{D})$.
Health professionals, especially those operating in newborn, pediatric, geriatric and oncology units should also be vaccinated ${ }^{27}(\mathbf{D})$.

Only in september of 2011, the use of the anti-pertussis vaccine in patients aged over 65 years was cleared by the U.S. Food and Drug Administration (FDA $)^{27}$ (D), as well as for patients with special clinical conditions such as chronic pneumopathy, heart disease, diabetes, HIV or other immunodeficiency conditions, chronic liver diseases, chronic alcoholism, asplenia and kidney failure. It is known that the morbidity of the disease is higher in these groups ${ }^{26-}$ ${ }^{-28}$ (D). Reinforcement with dTpa or dTpa-IPV induces a better immunological response in adults between 55 and 64 years of age than those aged over 65 , with a larger population and greater follow-up time necessary to evaluate the results in the latter population ${ }^{29}(\mathbf{B})$.

Some studies are evaluating the safety and importance of vaccination in pregnant women. The Brazilian Immunization Association (SBIm) and the Advisory Committee on Immunization Practices in the USA (ACIP) suggest for the vaccine to be given after the 20th week of pregnancy, or post-partum, if the mother has not been vaccinated previously, while there is no clearance on the vaccines for this specific group ${ }^{30.31}(\mathbf{D})$.

The vaccines are effective and immunogenic, and various studies have shown satisfactory antibody production response at the booster dose. This data may be correlated with an effective clinical protection response against whooping $\operatorname{cough}^{32}(\mathbf{A})^{25}(\mathbf{B})$.

In 2004, after some provinces in Canada introduced dTpa with a fifth component (Haemophilus influenzae type B) in adolescents between 14 and 16 years, an important reduction of $84 \%$ was observed in the disease in this age range, as well as groups with a lower age range, due to the probable effect of herd immunity ${ }^{33}(\mathbf{B})$.

In the same year, Australia introduced a booster with $\mathrm{dT}$ pa for adolescents between 15 and 17 years. However, owing to the elevated incidence of the disease in adolescents, some states such as New South Wales expanded the age range of the immunization program to 12 to 17 years and noted an effectiveness of 78\% (CI 95\% 60.7$87.6)^{33}(\mathbf{B})$, that is, the disease was reduced from 124 to $40.4 / 100,000^{34}(\mathbf{B})$. It was therefore shown that the booster dose could be used as an effective tool to control the disease $^{32}(\mathbf{A})^{33-35}(\mathbf{B})$.

In relation to the adverse effects of anti-pertussis vaccines for adults, there is a very similar safety profile to that observed in the $\mathrm{dT}$ vaccine, which is widely used in the national immunization program ${ }^{2}(\mathbf{D})$. The most 
common adverse effects are local reactions such as pain (61 to $69.2 \%$ ), edema (17.6 to $25.6 \%$ ) and erythema (21.1 to $27.1 \%)^{35}(\mathbf{B})$. Systemic adverse effects may occur, such as headache (30 to $31 \%$ ), body temperature above $37.5^{\circ} \mathrm{C}$ (5.5 to $8 \%$ ), fatigue (28.1 to $28.9 \%$ ), and gastrointestinal symptoms $(15.9 \text { to } 17.5 \%)^{36}(\mathbf{B})$.

The vaccines are contraindicated in cases of allergies of an anaphylactic nature to previous vaccinations or to any of the components of the vaccine ${ }^{37}(\mathbf{D})$. People with previous cases of encephalopathy without an identifiable cause in a 7-day period after the previous dose of vaccines containing pertussis components should only receive $\mathrm{dT}^{37}(\mathbf{D})$.

\section{Recommendation}

The anti-pertussis vaccines available in Brazil are acellular and present components against diphtheria, tetanus and whooping cough $(\mathrm{dTpa})^{19}(\mathbf{D})$ or components against diphtheria, tetanus, whooping cough and inactivated polio (dTpa-IPV) $)^{20.21}(\mathbf{D})$. The booster vaccine depends on the situation of the basic vaccine status in childhood ${ }^{22.27}(\mathbf{D})$ and is recommended because the antibodies of these diseases are low in individuals over 40 years ${ }^{24}(\mathbf{B})$. Adults that live or work with infants less than one year old should receive a single booster ${ }^{23}(\mathbf{B})^{22.27}(\mathbf{D})$. This therapeutic resource was only cleared for the elderly with chronic diseases in $2011^{26.28}(\mathbf{D})$, and preliminary results demonstrate better immunological response for adults between 55 and 64 years $^{29}(\mathbf{B})$. It should be remembered that Brazil has maintained the eradication of the poliomyelitis disease for years ${ }^{1.6}(\mathbf{D})$ and, as the effective clinical protection of anti-pertussis vaccines is against whooping $\operatorname{cough}^{32}(\mathbf{A})^{25}(\mathbf{B})$, it is recommended to use $\mathrm{dTpa}^{19}(\mathbf{D})$, as there would be no greater benefit in using the combined vaccine with inactivated poliomyelitis (dTpa-IPV) ${ }^{20.21}(\mathbf{D})$. They are contraindicated in the case of previous anaphylactic allergic reaction to the vaccination or any component of the vaccine ${ }^{37}(\mathbf{D})$.

\section{IS THERE A BENEFIT TO THE USE OF BCG VACCINES?}

The BCG (Bacille de Calmette et Guérin) vaccine originates from attenuated and avirulent strains of Mycobacterium bovis, which through immunogenic properties are able to stimulate protection against serious infection and illness caused by Mycobacterium tuberculosis, such as tuberculous meningitis and miliary tuberculosis. It has been used since $1921^{38}(\mathbf{B})$.

The existing recommendation is for newborns up to the first month old. The loss of the protective effect of the BCG vaccine over time has led to some countries adopting revaccination ${ }^{39.40}(\mathbf{B})$. In Brazil, the Ministry of Health has recommended the BCG revaccination of the 6- to 14-year population since 1994. Nevertheless, studies on BCG revaccination (including in Brazil) has not shown protection by the second dose against tuberculosis in revaccinated adolescents $s^{38.41-44}(\mathbf{B})^{45}(\mathbf{C})$.

BCG revaccination has been studies both in populations with persistent protective effects as well as those where the protective effects was lost, with no differences between the groups. The incidence of tuberculosis was 16.5 and 12.9 per 100,000 people/year in vaccinated and revaccinated people respectively, without significant differences, as the reduction of the risk upon revaccination had $\mathrm{RR}=1.28$ with CI 95\% 0.92-1.77 ${ }^{39}(\mathbf{B})$. In Brazil, the incidence of tuberculosis between those vaccinated according to the usual calendar and those revaccinated is greater without the booster, but maintains the absence of benefit, with 29.3 versus 30.2 per 100,000 people/year, with $R R=0.94$ and $C I$ 95\% 0.76-1.28 ${ }^{41}(\mathbf{B})$. It would be necessary to immunize 4963 people to avoid the development of one case of tuberculosis, therefore, there is no adequate cost-benefit relationship ${ }^{40}(\mathbf{B})$.

Thus, in 2006, the Ministry of Health recommended the suspension of BCG revaccination. It is also not recommended to revaccinate the indigenous population. Therefore, in adults, only those in contact with leprosy should be revaccinated, and, even then, only once ${ }^{1}(\mathbf{D})$. Currently in Brazil, the only recommendation in adults relates to household contact with leprosy patients ${ }^{38}(\mathbf{B})$.

The possibility of a secondary vaccination of BCG for those with HIV is still being evaluated, with the benefits yet to be proven ${ }^{42.44}(\mathbf{B})$.

The dose and frequency of application is two doses of $0.1 \mathrm{~mL}$ each, with a 6 month interval between them.

Each $0.1 \mathrm{~mL}$ dose of reconstituted intradermic BCG vaccine contains:

- Bacille de Calmette et Guérin ------------ $0.1 \mathrm{mg}$

- Sodium glutamate-------------0.52 mg

- Saline solution at $0.9 \%$ (q.s.p.)----0.1 mL

The adverse effects of the application of BCG vaccine are rare and generally occur due to incorrect application, such as too deep or using an excessive dose of the immunobiological component. In up to $10 \%$ of people vaccinated the formation of an ulcerate lesion occurs, which may take months to heal completely. Other presentations include abscess at the injection site and floating nodes with fistulization, osteitis, osteomyelitis, and generalized infection may possibly occur. Serious allergic reactions (anaphylaxis) are rare. 


\section{Recommendations}

The BCG is recommended for newborns and infants aged up to one month at two doses of $01 . \mathrm{mL}$, at 6 months intervals.

The BCG vaccine has few adverse effects, generally resulting from incorrect application. Currently in Brazil, the only recommendation for adults relates to household contact with leprosy patients ${ }^{38}(\mathbf{B})$.

\section{WHICH PNEUMOCOCCAL VACCINES ARE AVAILABLE IN BRAZIL?}

There are currently two types of vaccine employing different technologies. The first type of vaccine is the 23-valent polysaccharide (VPPS-23) vaccine, an unconjugated formulation that has antigens to the walls of 23 serotypes. These are responsible for around $90 \%$ of the strains implicated in invasive pneumococcal disease (IPD), and the vaccine was developed primarily for use in adults ${ }^{46}(\mathbf{D})$.

The second type available uses a carrier protein conjugated to the vaccine's polysaccharide antigens, and is therefore denominated a conjugate vaccine. This combination increases the immunogenic effect and duration of the immunological memory, providing longer lasting protection. Two new formulations conjugated with antigens of $10(\mathrm{PCV} 10)^{47}(\mathbf{D})$ and $13(\mathrm{PCV} 13)^{48}(\mathbf{D})$ serotypes were approved in Brazil for the prevention of IPD in children aged up to two years of age (PCV10) and children aged between two months and six years (PCV13). PCV13 has already been approved for use in adults in the European Community and some countries in Latin America, and was cleared by the FDA in September 2011, and by the ANVISA, in Brazil, in 2013.

The polysaccharide vaccine is widely used in adults and the elderly. It produces a short immune response with low permanence for the production of antibodies, mainly after 65 years of age ${ }^{49}(\mathbf{B})$. In some specific populations, revaccination was attempted five years after the first dose, without satisfactory results, as the improvement in the level of antibodies is transitory, with possible hyporesponsiveness ${ }^{50.51}(\mathbf{B})$. While conjugate vaccines are habitually used in children less than 2 years old, they may also be applied in adults, stimulating the immune response with the production of antibodies with better memory effects.

\section{Recommendation}

In Brazil, there are two types of pneumococcal vaccines: the polysaccharide vaccine ${ }^{46}(\mathbf{D})$, and the conjugate vaccines $^{47.48}(\mathbf{D})$.

\section{What IS THE IMPORTANCE OF S. PNEUMONIAE AS A CAUSE OF SERIOUS RESPIRATORY DISEASE?}

S. pneumoniae or pneumococcus is a Gram positive bacterium, generally encapsulated, that is present in pairs or short chains in the form of a spear. There are approximately 92 immunologically distinct serotypes capable of leading to various diseases. Of these 92 serotypes, 20 are responsible for $75 \%$ of invasive infections.

Pneumococcal infection is classified either as carrier state, noninvasive disease (NID) - localized purulent infection, such as sinusitis, otitis media, conjunctivitis and nonbacteremic pneumonia - or Invasive Pneumococcus Disease (IPD) - pneumonia with bacteremia, bacteremia, meningitis, and endocarditis, which also constitute the forms of presentation in adults and the elderly ${ }^{52}(\mathbf{B})$.

S. pneumoniae is the most frequent agent in community-acquired pneumonia (CAP), varying between 35 and $50 \%$ of the cases, ahead of H. influenzae, M. pneumoniae, C. pneumoniae, Legionella sp, respiratory viruses and enterobacteria. As in other parts of the world, S. pneumoniae is also the most common agent for CAP in Latin America (35\%). The mortality rate for CAP increases progressively from the age of 60 years, reaching levels 10 times higher than for children less than one year old among individuals aged over 80 years $^{53}$ (D).

IPD has a high morbidity and high mortality rate. Even with pneumococcus vaccination administered to the elderly, there are cases of pneumonia, sometimes complicated with empyema, bacteremia without a defined focus, meningitis, spontaneous bacterial peritonitis, septic arthritis, endocarditis and osteomyelitis. There is also the possibility of a patient having associations with the aforesaid conditions. Mortality within 30 days is $16 \%$ and does not depend on the person being vaccinated or $\operatorname{not}^{54}(\mathbf{B})$.

The IPD rate changed significantly after the use of conjugate vaccine 7 (PCV7) in children under 5, falling from 252 cases per 100,000 people/year (1991-1997) to 87 cases per 100,000 people/year $(2001-2006)^{55}$ (B) or 19 29.9 cases per 100,000 people/year (1998-1999) to 11.2 18 cases per 100,000 people/year ${ }^{56}(\mathbf{B})$. However, the same fact did not occur with the use of pneumococcus vaccine (VPPS-23) in adults, remaining at 60 cases per 100,000 people/year in the first period and 78.9 cases per 100,000 people/year in the second $\operatorname{period}^{55}(\mathbf{B})$.

The IPD rate in those aged over 65 years is estimated at 23 cases per 100,000 people/year; however, this increases to 460 cases per 100,000 people/year if the elderly present neoplasms as comorbidity ${ }^{57}(\mathbf{B})$. 
Considering the substantial morbidity and high rate of early mortality from IPD in adults, work evaluating pneumococcus vaccination defines it as cost effective ${ }^{58.59}(\mathbf{B})$.

\section{Recommendation}

S. pneumoniae causes disease in the respiratory tract, such as high infections (sinusitis and otitis) and pneumonia. It can also lead to meningitis, bacteremia and sepsis. Its capacity for invasiveness produces IPD, which has high morbidity and mortality ${ }^{54.58,59}(\mathbf{B})$.

\section{What ARE THE RECOMMENDATIONS FOR THE PNEUMOCOCCUS VACCINE?}

The current recommendation for pneumococcus vaccination by the CDC includes ${ }^{60.61}(\mathbf{D})$ :

- all adults aged 65 years or older;

- any person aged from 2 to 64 years with a chronic diseases, such as cardiac or pulmonary diseases, sickle cell anemia, diabetes, alcoholism, cirrhosis of the liver, cerebrospinal fistula, or cochlear implants;

- any person between 2 and 64 years of age with immunosuppression conditions such as Hodgkin's disease, lymphoma or leukemia, kidney failure, multiple myeloma, nephrotic syndrome, HIV infection or AIDS, asplenia or splenic disease and organ transplant;

- any person between 2 and 64 years of age that uses immunosuppressant drugs, such as long term corticosteroid, drugs used in the treatment of cancer, and radiotherapy;

- adults between 19 and 64 years that are smokers or have asthma;

- long-term residents of nursing homes and institutions.

In April, 2013, a new indication of the 13 valent conjugate vaccine was released in Brazil for healthy adults over 50 years. In Brazil, as well as in other locations in the world, vaccine coverage against pneumococcus is still not widely used in clinical practice ${ }^{62-67}(\mathbf{B})$.

The use of electronic reminders for all patients over 65 years could increase the prescription of the pneumococcus vaccine from 13.1 to $19.5 \%{ }^{68}(\mathbf{B})$. Another way of increasing the prescription of the vaccine is not to miss the opportunity to vaccinate patients hospitalized for chronic diseases ${ }^{63}(\mathbf{B})$.

\section{Recommendation}

Pneumococcus vaccines are recommended for the prevention of pneumococcal diseases, especially IPD, in specific groups of adults ${ }^{60.61}(\mathbf{D})$. Programs are required to clarify the importance of the uses of these therapeutic resources to increase the coverage of the vaccine in the population $^{63.68}(\mathbf{B})$.

\section{Are there Differences between POLYSACCHARIDE AND CONJUGATE PNEUMOCOCCUS VACCINES?}

The 23-valent polysaccharide vaccine (VPPS-23) presents low immunogenicity in children less than two years old, and does not induce immunological memory as a result of not sensitizing the $\mathrm{T}$ cell ( $\mathrm{T}$-cell independent activation ${ }^{69}(\mathbf{D})$. Conjugate vaccines include polysaccharides conjugated to a carrier protein and therefore have greater immunogenic effect, longer immunological memory and provide longer lasting protection. However, having used a polysaccharide vaccine previously reduces the benefits achieved with the conjugate vaccine ${ }^{70}(\mathbf{B})$. For example, as of 2000, the use of the PCV7 vaccine in children less than nine years old resulted in a significant reduction of IPD among vaccinated (direct effect) and unvaccinated individuals of all ages, particularly patients aged over 65 years (herd effect). Two new formulations conjugated with antigens for 10 (PCV10) and 13 (PCV13) serotypes were recently approved in the USA and Brazil for the prevention of IPD in children aged up to two years (PCV10) and children between two months and six years old (PCV13 ${ }^{69}(\mathbf{D})$. The PCV13 was also approved for adults over 50 years.

The general effectiveness of VPPS-23 is 74\% (CI 95\%, $56 \%-85 \%$ ), according to randomized studies, and $52 \%$ (CI $95 \%, 39 \%-63 \%$ ), according to observational studies ${ }^{71}(\mathbf{D})$. However, its effectiveness in elderly individuals is inferior to that observed in healthy adults ${ }^{72}(\mathbf{B})$. Also, it enables a significant reduction in IPD (OR=0.26; CI 95\% $0.15-0.46)^{73}(\mathbf{A})$.

The effectiveness against all-cause pneumonia has not yet been demonstrated ${ }^{73}(\mathbf{A})^{74}(\mathbf{B})$ and the use of VPPS-23 has not been associated with a lower mortality rate in the vaccinated group $(\mathrm{OR}=0.87 \text { with } \mathrm{CI} 95 \% 0.69-1.10)^{73}(\mathbf{A})$. The duration of the immune response to VPPS-23 declines with time and age (over 65 years), with the levels of antibodies reaching pre-vaccination levels after 4 to 7 years $^{50.51}(\mathbf{B})$. The benefit of revaccination was demonstra- 
ted in adults under 65 years, with tolerance or hyporesponsiveness possibly occurring ${ }^{50.51,75}(\mathbf{B})$.

We still need robust trials that define the benefits of new conjugate vaccines for adults and the elderly ${ }^{71.76}(\mathbf{D})$.

Pneumococcal vaccination in adults is safe, with few reports of adverse events associated with the injection (transitory pain and redness) and light systemic symptoms such as fever and myalgia, which persist for less than 48 hours. It is not recommended for pregnant women ${ }^{57}(\mathbf{B})$.

\section{Recommendation}

There are differences between polysaccharide and conjugate pneumococcus vaccines. Conjugate vaccines produce a longer lasting and more intense immunological response than non conjugate vaccines ${ }^{70}(\mathbf{B})$. VPPS-23 significantly reduces IPD, but up to now, it has not demonstrated a reduction in the amount of pneumonia or mortality ${ }^{73}(\mathbf{A})^{74}(\mathbf{B})$, with less benefits for patients over 65 years old ${ }^{71.76}(\mathbf{D})$. There is no benefit in revaccinating adults less than 65 years old, as this may cause tolerance or hyporesponsiveness. There is also discussion about the recommendation fro patients with reduced immunity ${ }^{50.51,74}(\mathbf{B})$. Pneumococcus vaccination in adults is safe, with few reports of adverse events, but is not recommended for pregnant women ${ }^{57}(\mathbf{B})$.

\section{What IS THE DOSE AND APPLICATION METHOD OF THE PNEUMOCOCCUS VACCINE?}

The polysaccharide vaccine should be applied in a single dose of $0.5 \mathrm{~mL}$ intramuscularly or subcutaneously ${ }^{46}(\mathbf{D})$. A booster after five years is suggested in patients with reduced immunity, but there is discussion about this recommendation, as studies show a lower antigenic effect after use of the booster dose. The conjugate vaccine PCV13 for adults should be applied in a single dose of $0.5 \mathrm{~mL}$, intramuscularly ${ }^{48}(\mathbf{D})$.

\section{IS THERE A BENEFIT TO COMBINED VACCINATIONS FOR THE PREVENTION OF INFECTIOUS RESPIRATORY DISEASES IN ADULTS?}

Studies on the combine used of flu and pneumococcus vaccines in patients with chronic diseases are common.

Flu and pneumococcus vaccinations are recommended in the Brazilian and global guidelines for heart failu$\mathrm{re}^{77-79}(\mathbf{D})$, as respiratory infections are the third main cause of hospitalization for decompensated heart failure ${ }^{77.78}(\mathbf{D})$. Also, there is an association between respiratory infections and increased risk of cardiac ischemia ${ }^{80.81}(\mathbf{B})$ and strokes $^{82}(\mathbf{B})$. These two vaccinations reduce respiratory infections, hospitalizations and acute cardiovascular events $^{63}(\mathbf{B})$.

In order to assess the benefit of 23 polyvalent pneumococcal vaccine in patients with chronic obstructive pulmonary disease (COPD), the number of exacerbations and pneumonia as well as mortality was assessed. There were no significant differences in the number of exacerbations between those vaccinated and unvaccinated (OR=0.58 with CI 95\% 0.30-1.13), as well as the number of events of pneumonia (OR=0.72 with CI 95\% 0.51 1.01). The evaluation of mortality for all causes within 48 months of vaccination or mortality due to cardiorespiratory causes had no significant differences, either $(\mathrm{OR}=0.94$ with CI 95\% 0.67-1.33 and OR=1.07 with CI 95\% 0.69-1.66, respectively) ${ }^{83}(\mathbf{A})$. The 23 polyvalent pneumococcus vaccine does not change the frequency and severity of infectious exacerbations in patients with bronchiectasis ${ }^{84}(\mathbf{B})$. Asthmatic patients present a lower number of specific antibodies after vaccination in relation to non-asthmatics, which keeps them at a high risk of developing IPD, mainly if they depend on corticoids ${ }^{85}(\mathbf{B})$. Using flu vaccine in patients with COPD does not cause adverse reactions, does not lead to exacerbation, does not worsen pulmonary function and the symptoms of dyspnea, and does not increase the restriction on exercise, regardless of any level of obstruction in the air flow ${ }^{86}(\mathbf{B})$. Patients with COPD should receive vaccination against influen$\mathrm{za}^{87-89}(\mathbf{B})$, which reduces mortality in $41 \%$ of $\operatorname{cases}^{89}(\mathbf{B})$. There is a benefit to the combined use of flu and pneumococcus vaccines with the reduction of hospitalizations, pneumonia and mortality ${ }^{90-92}(\mathbf{B})$, though the reduction in mortality is influenced more by the protection of the flu vaccine ${ }^{89.93}(\mathbf{B})$.

The use of PCV7 has led to a reduction in the IPD rate in children under 5 with sickle cell anemia, with a reduction in IPD in $93.4 \%$ of cases. Before this vaccine (1995-1999) there were 2044 cases per 100,000 people/year and, after the introduction of the vaccine (20012004), this number fell to only 134 cases per 100,000 people/year. This benefit was not found for age ranges other than that described, as there were no significant differences in the IPD rate in patients over 5 after use of the conjugate vaccine (161 to 99 cases in 100,000 people/ year, with $\mathrm{p}=0.36)^{94}(\mathbf{B})$.

Patients with asplenia or splenectomy should receive vaccines for Haemophilus influenzae B and pneumococcus vaccine for the increased risk of infection by encapsulated microorganisms, particularly S. pneumoniae, Haemophilus influenzae tipo B and Neisseria meningitidis. Special care is 
necessary in this population, as vaccine coverage might not reach $50 \%$ of applicable cases ${ }^{95}(\mathbf{B})$. Splenectomized adults with an average age of 29.6 years already vaccinated with 23 polyvalent polysaccharide vaccine had $5 \%$ less cases of IPD in the clinical follow-up, without clinical benefits when adding another PCV7 conjugate vaccination, though with an increase in immunogenic response ${ }^{96}(\mathbf{B})$. Patients splenectomized due to hematologic malignancies respond worse to the polysaccharide pneumococcus vaccines compared to those splenectomized due to trau$\mathrm{ma}$, and require closer monitoring ${ }^{97}(\mathbf{B})$.

Given that smoking is associated with an increased risk of respiratory infections, with populations of smokers, former smokers and nonsmokers have been studied to evaluate adherence to the use of flu and pneumococcus vaccines. Former smokers have a $17 \%$ greater change of using flu vaccines than nonsmokers ( $\mathrm{OR}=1.17$ with $\mathrm{CI}$ $95 \% 1.12-1.22)$ and a $32 \%$ greater chance of using pneumococcus vaccine than nonsmokers $(\mathrm{OR}=1.32$ with $\mathrm{CI}$ 95\% 1.24-1.41). Current smokers use these therapeutic resources less ( $\mathrm{OR}=0.75$ with CI 95\% 0.71-0.80), but should be encouraged to receive the prevention of vaccines and stop using tobacco ${ }^{98}(\mathbf{B})$.

The real benefit of using the pneumococcus vaccine in those with acquired immunodeficiency syndrome is no yet $\mathrm{known}^{99}(\mathbf{B})$, as the only randomized clinical trial demonstrated that there was no increase in antibodies after vaccination, whether polysaccharide or conjugate ${ }^{100}(\mathbf{A})$. Likewise, there is debate regarding the use of the vaccine in alcoholics, as there are reported cases of death from streptococcal sepsis after vaccination ${ }^{101.102}(\mathbf{C})$.

There are no studies in adults using pneumococcus vaccines in those with CFS leak syndrome, only in children ${ }^{103}(\mathbf{B})$.

\section{Recommendation}

There are benefits in using combined vaccines, as immunization with flu and pneumococcus vaccines reduces hospitalizations, respiratory infections and cardiovascular events in patients with heart disease ${ }^{63}(\mathbf{B})$; and hospitalizations, pneumonia and mortality in those with CO$\mathrm{PD}^{90-92}(\mathbf{B})$. The association between vaccines for Haemophius influenzae $\mathrm{B}$ and and pneumococcus reduces the cases of IPD by $5 \%$ in patients with asplenia or those splenectomized for all reasons ${ }^{96}(\mathbf{B})$, with a worse response for those splenectomized due to hematologic malignancies ${ }^{97}(\mathbf{B})$.
The 93.4\% reduction in IPD cases in children less than 5 years old with sickle cell anemia was not confirmed in adult and elderly populations ${ }^{94}(\mathbf{B})$.

\section{Conflict of interest}

Lundgren F: Received fees for presenting lectures sponsored by Pfizer. He has received medical consultancy fees sponsored by Pfizer.

Chatkin JM: Received reimbursement for appearing at congresses sponsored by the Wyeth and Pfizer. He has received fees for presenting lectures sponsored by the Wyeth and Pfizer.

Corrêa RA: Received reimbursement for appearing at congresses sponsored by Pfizer. He has received fees for the presentation of lectures and medical consultancy sponsored by Pfizer.

Figueiredo MRF: Received reimbursement for medical consultancy and lectures sponsored by Pfizer

Stirbulov R: Received reimbursement for participating in congresses by GSK, Boehering-Ingelheim and Aché. He has received fees for presentations at symposiums sponsored by Takeda, Pfizer, GSK and Boehering-Ingelheim. He has received fees for medical consultancy sponsored by Boehering-Ingelheim, GSK, Novartis and Aché. He has received fees for clinical research sponsored by Takeda and Novartis.

\section{References}

1. Brazilian Ministry of Health. Vaccination calendar for adults and the elederly. Available at: http://portal.saude.gov.br/portal/saude/visualizar_texto.cfm? Idtxt=21464. Access on: 11/5/2011.

2. www.anvisa.gov.br. Access on: 12/16/2011.

3. Neuzil KM, Maynard C, Griffin MR, Heagerty P. Winter respiratory viruses and health care use: a population-based study in the northwest United States. Clin Infect Dis 2003;37:201-7.

4. Gershon AA, Gardner P, Peter G, Nichols K, Orenstein W. Quality standards for immunization. Guidelines from the Infectious Diseases Society of America. Clin Infect Dis 1997;25:782-6.

5. www.cdc.gov Acesso em: 12/16/11

6. www.who.int/in Acesso em: 12/16/11.

7. Hurley LP, Wortley P, Allison MA, O’Leary S, Daley MF, Babbel C, et al. Seasonal influenza vaccination in adults: practice and attitudes about collaborative delivery with community vaccinators. Vaccine 2011;29:864955.

8. Fiore AE, Bridges CB, Cox NJ. Seasonal influenza vaccines. Curr Top Microbiol Immunol 2009;333:43-82

9. Lai $\mathrm{H}$, Aronow WS, Gutwein AH. Prevalence of influenza vaccination and pneumococcal vaccination in elderly and high-risk patients seen in a university general medicine clinic. Am J Ther 2008;15:528-30.

10. Forrest BD, Steele AD, Hiemstra L, Rappaport R, Ambrose CS, Gruber WC. A prospective, randomized, open-label trial comparing the safety and efficacy 
of trivalent live attenuated and inactivated influenza vaccines in adults 60 years of age and older. Vaccine 2011;29:3633-9.

11. Song JY, Cheong HJ, Woo HJ, Wie SH, Lee JS, Chung MH, et al. Immunogenicity and safety of trivalent inactivated influenza vaccine: a randomized, doubleblind, multi-center, phase 3 clinical trial in a vaccinelimited country. J Korean Med Sci 2011;26:191-5.

12. www.eswi.org Acesso em: 12/16/11.

13. www.nih.gov Acesso em: 12/16/11.

14. Thompson DL, Jungk J, Hancock E, Smelser C, Landen M, Nichols M, et al. Risk factors for 2009 pandemic influenza A (H1N1)-related hospitalization and death among racial/ethnic groups in New Mexico. Am J Public Health 2011;101:1776-84.

15. Nichol KL, Margolis KL, Wouremna J, von Sternberg T. Effectiveness of influenza vaccine in the elderly. Gerontology 1996;42:274-9.

16. Diego C, Vila-Córcoles A, Ochoa O, Rodriguez-Blanco T, Salsench E, Hospital $\mathrm{I}$, et al. Effects of annual influenza vaccination on winter mortality in elderly people with chronic heart disease. Eur Heart J 2009;30:209-16.

17. Nichol KL, Nordin J, Mullooly J, Lask R, Fillbrandt K, Iwane M. Influenza vaccination and reduction in hospitalizations for cardiac disease and stroke among the elderly. N Engl J Med 2003;348:1322-32.

18. Sandoval C, Walter SD, Krueger P, Smieja M, Smith A, Yusuf S, et al. Risk of hospitalization during influenza season among a cohort of patients with congestive heart failure. Epidemiol Infect 2007; 135:574-82.

19. 19. Package insert for adsorbed vaccine against diphtheria, tetanus, pertussis (acellular). Booster.

20. Package insert for adsorbed vaccine against diphtheria, tetanus, pertussis (acellular) and Polio I, II and III (inactivated).

21. Package insert for adsorbed vaccine against diphtheria, tetanus, pertussis (acellular) and Polio I, II and III (inactivated).

22. Brazilian Association of Immunization. Vaccination calendar for adults and the elederly, 2011. Available at: http://www. sbim. org.br/sbim_ calendarios_2011_adulto.pdf. Access on: 11/5/2011.

23. Carvalho AP, Pereira EM. Acellular pertussis vaccine for adolescents. J Pediatr 2006;82(3 Suppl):S15-24.

24. Quinn HE, McIntyre PB. The impact of adolescent pertussis immunization, 2004-2009: lessons from Australia. Bull World Health Organ 2011;89:666-74.

25. Grimprel E, von Sonnenburg F, Sänger R, Abitbol V, Wolter JM, Schuerman $\mathrm{LM}$, et al. Combined reduced-antigen content diphtheria-tetanus-acellular pertussis and polio vaccine (dTpa-IPV) for booster vaccination of adults. Vaccine 2005;23:3657-67.

26. Centers for Disease Control and Prevention (CDC). Updated recommendations for use of tetanus toxoid, reduced diphtheria toxoid and acellular pertussis (Tdap) vaccine from the Advisory Committee on Immunization Practices, 2010. MMWR 2011;60:13-15.

27. Centers for Disease Control and Prevention (CDC). Recommended adult immunization schedule - United States, 2011. MMWR Morb Mortal Wkly Rep 2011;60:1-4.

28. Centers for Disease Control and Prevention (CDC). FDA approval of expanded age indication for a tetanus toxoid reduced diphitheria and acellular pertussis vaccine. MMWR Morb Mortal Wkly Rep 2011;60:1279-80.

29. Van Damme P, McIntyre P, Grimprel E, Kuriyakose S, Jacquet JM, Hardt K, et al. Immunogenicity of the reducedantigen-content dTpa vaccine (Boostrix $(\circledR)$ in adults 55 years of age and over: a sub-analysis of four trials. Vaccine 2011;29:5932-9.

30. Centers for Disease Control and Prevention (CDC). Updated recommendations for use of tetanus toxoid, reduced diphtheria toxoid and acellular pertussis vaccine (Tdap) in pregnant women and persons who have or anticipate having close contact with an infant aged $<12$ months. Advisory Committee on Immunization Practices (ACIP), 2011.MMWR Morb Mortal Wkly Rep 2011;60:1424-6.

31. Brazilian Association of Immunization. Vaccination calendar for Women, 2011. Available at: http://www.sbim.org.br/sbim_calendarios_2011_mulher. pdf. Access on: 11/5/2011

32. Halperin SA, Smith B, Russel M, Scheifele D, Mills E, Hasselbach P, et al. Adult formulation of a five component acellular pertussis vaccine combined with diphtheria and tetanus toxoids and inactivated poliovirus vaccine is safe and immunogenic in adolescents and adults. Pediatr Infect Dis J 2000;19:276-83.

33. Greemberg DP, Doemland M, Bettinger JA, Scheifele DW, Halperin SA; IMPACT Investigators, et al. Epidemiology of pertussis and Haemophilus influenza type B disease in Canada with exclusive use of a diphtheria-tetanusacellular pertussis-inactivated poliovirus-Haemophilus influenzae type B pediatric combination vaccine and an adolescent-adult tetanusdiphtheria- acellular pertussis vaccine: implications for disease prevention in the United States. Pediatr Infect Dis J 2009;28:521-8.

34. Rank C, Quinn HE, McIntyre PB. Pertussis vaccine effectiveness after mass immunization of high school students in Australia. Pediatr Infect Dis J 2009;28:152-3.

35. Viney KA, McAnulty JM, Campbell-Lloyd S. Pertussis in New South Wales, 1993-2005: the impact of vaccination policy on pertussis epidemiology. N S W Public Health Bulletin 2007;06:55 PM-61.

36. Blatter M, Friedland LR, Weston WM, Li P, Howe B. Immunogenicity and safety os a tetanus toxoid, reduced diphteria toxoid and three-component acellular pertussis vaccine in adults 19-64 years of age. Vaccine 2009;27:76572 .

37. Bricks LF. Coqueluche. In: Neto VA, ed. Atualizações, orientações e sugestões sobre Imunizações. $1^{\mathrm{a}}$ ed. São Paulo: Segmento Farma; 2011. p.167-75.

38. Barreto ML, Pereira SM, Ferreira AA. BCG vaccine: efficacy and indications for vaccination and revaccination. J Pediatr 2006;82:S45-54.

39. 39. Leung CC, Tam CM, Chan SL, Chan-Yeung M, Chan CK, Chang KC. Efficacy of the BCG revaccination programme in a cohort given BCG vaccination at birth in Hong Kong. Int J Tuberc Lung Dis 2001;5:717-23.

40. Rahman M, Sekimoto M, Hira K, Koyama H, Imanaka Y, Fukui T. Is Bacillus Calmette-Guerin revaccination necessary for Japanese children? Prev Med 2002;35:70-7.

41. Rodrigues LC, Pereira SM, Cunha SS, Genser B, Ichihara MY, Brito SC, et al. Effect of BCG revaccination on incidence of tuberculosis in school-aged children in Brazil: the BCG-REVAC cluster-randomised trial. Lancet 2005;366:1290-5.

42. Barreto ML, Pereira SM, Pilger D, Cruz AA, Cunha SS, Sant'Anna C, et al. Evidence of an effect of BCG revaccination on incidence of tuberculosis in school-aged children in Brazil: second report of the BCG-REVAC clusterrandomised trial. Vaccine 2011;29:4875-7.

43. Roth AE, Benn CS, Ravn H, Rodrigues A, Lisse IM, Yazdanbakhsh M, et al. Effect of revaccination with BCG in early childhood on mortality: randomised trial in Guinea-Bissau. BMJ 2010;340:c671.

44. von Reyn CF, Mtei L, Arbeit RD, Waddell R, Cole B, Mackenzie T, et al. Prevention of tuberculosis in Bacille Calmette-Guérin-primed, HIV-infected adults boosted with an inactivated whole-cell mycobacterial vaccine. AIDS 2010;24:675-85.

45. Dantas OM, Ximenes RA, Albuquerque MF, Silva NL, Montarroyos UR, Souza WV, et al. A case-control study of protection against tuberculosis by BCG revaccination in Recife, Brazil. Int J Tuberc Lung Dis 2006;10:536-41.

46. Package insert of the pneumococcal polysaccharide vaccine PneumovaxMerck http://www.merck.com/product/usa/pi_circulars/p/pneumovax_23/ pneumova_pi.pdf

47. Package insert for conjugate pneumococcal vaccine-Sinforix - GSK - http:// www.dromayor.com.co/diccionario/PLM/productos/31020_392.htm

48. Package insert for conjugate pneumococcal vaccine - Prevenar13 - Pfizer. www.pfizer. com.br/arquivoPDF.aspx?200,pdf

49. Park S, Nahm MH. Older adults have a low capacity to opsonize pneumococci due to low IgM antibody response to pneumococcal vaccinations. Infect Immun 2011;79:314-20.

50. Jackson LA, Baxter R, Naleway AL, Belongia EA, Baggs J. Patterns of pneumococcal vaccination and revaccination in elderly and non-elderly adults: a Vaccine Safety Datalink study. BMC Infect Dis 2009;09:37 AM.

51. Crum-Cianflone NF, Huppler Hullsiek K, Roediger M, Ganesan A, Patel S, Landrum ML, et al. A randomized clinical trial comparing revaccination with pneumococcal conjugate vaccine to polysaccharide vaccine among HIV-infected adults. J Infect Dis 2010;202:1114-25.

52. Center for Disease Control and Prevention. Pneumococcal disease. Epidemiology and prevention of vaccine-preventable diseases. The pink book: course textbook. 11a ed. Atkinson W, Wolfe S, Hamborsky J, McIntyre L, editores. Washington: Public Health Foundation; 2009. p.217-30.

53. Corrêa RA, Lundgren FL, Pereira-Silva JL, Frare e Silva RL, Cardoso AP, Lemos AC, et al. Brazilian guidelines for community-acquired pneumonia in immunocompetent adults - 2009. J Bras Pneumol 2009;35:574-601.

54. Rueda AM, Serpa JA, Matloobi M, Mushtaq M, Musher DM. The spectrumof invasive pneumococcal disease at an adult tertiary care hospital in the early 21st century. Medicine 2010;89:331-6.

55. Lacapa R, Bliss SJ, Larzelere-Hinton F, Eagle KJ, McGinty DJ, Parkinson AJ, et al. Changing epidemiology of invasive pneumococcal disease among White Mountain Apache persons in the era of the pneumococcal conjugate vaccine. Clin Infect Dis 2008;47:476-84. 
56. Rosen JB, Thomas AR, Lexau CA, Reingold A, Hadler JL, Harrison LH, et al; CDC Emerging Infections Program Network. Geographic variation in invasive pneumococcal disease following pneumococcal conjugate vaccine introduction in the United States. Clin Infect Dis 2011;53:137-43.

57. Ripoll ME, Valenzuela BMT, Vergara FR, Abarca VK, Muñoz MA, Jiménez de la Jara J, et al. 23-valent pneumococcal vaccine. Statement of the Consultive Committee of Immunizations on behalf of the Chilean Infectious Diseases Society: February 2010. Rev Chilena Infectol 2010;27:133-7.

58. Ogilvie I, Khoury AE, Cui Y, Dasbach E, Grabenstein JD, Goetghebeur M. Costeffectiveness of pneumococcal polysaccharide vaccination in adults: a systematic review of conclusions and assumptions. Vaccine 2009;27:4891904.

59. Smith KJ, Zimmerman RK, Lin CJ, Nowalk MP, Ko FS, McEllistrem MC, et al. Alternative strategies for adult pneumococcal polysaccharide vaccination: a cost-effectiveness analysis. Vaccine 2008;26:1420-31.

60. World Health Organization. 23-valent pneumococcal polysaccharide vaccine. WHO position paper. Wkly Epidemiol Rec 2008;83:373-84.

61. Centers for Disease Control and Prevention (CDC); Advisory Committee on Immunization Practices. Updated recommendations for prevention of invasive pneumococcal disease among adults using the 23 -valent pneumococcal polysaccharide vaccine (PPSV23). MMWR Morb Mortal Wkly Rep 2010;59:1102-6.

62. Martins WA, Ribeiro MD, Oliveira LB, Barros LS, Jorge AC, Santos CM, et al. Influenza and pneumococcal vaccination in heart failure: a little applied recommendation. Arq Bras Cardiol 2011;96:240-5.

63. Bratzler DW, Houck PM, Jiang H, Nsa W, Shook C, Moore L, et al. Failure to vaccinate Medicare inpatients: a missed opportunity. Arch Intern Med 2002;162:2349-56.

64. Jones LG, Zhang Y, Ahmed MI, Ekundayo OJ, Akhter S, Sawyer P, et al Understanding the reasons for the underuse of pneumococcal vaccination by community-dwelling older African Americans. J Am Geriatr Soc 2010;58:2323-8

65. Jacups SP, Cheng A. The epidemiology of community acquired bacteremic pneumonia, due to Streptococcus pneumoniae, in the top end of the northern territory, Australia: over 22 years. Vaccine 2011;29:5386-92.

66. Martinelli D, Tafuri S, Caputi G, Fortunato F, Reggio P, Germinario C, et al. Eight years of active proposal of pneumococcal 23 -valent polysaccharide vaccine: survey on coverage rate among elderly and chronic patients. Am J Infect Control 2010;38:e8-e15

67. Lu PJ, Nuorti JP. Pneumococcal polysaccharide vaccination among adults aged 65 years and older, U.S., 1989-2008. Am J Prev Med 2010;39:287-95.

68. Loo TS, Davis RB, Lipsitz LA, Irish J, Bates CK, Agarwal K, et al. Electronic medical record reminders and panel management to improve primary care of elderly patients. Arch Intern Med 2011;171:1552-8.

69. O'Brien KL, Hochman M, Goldblatt D. Combined schedules of pneumococcal conjugate and polysaccharide vaccines: is hyporesponsiveness an issue? Lancet Infect Dis 2007;7:597-606.

70. Lazarus R, Clutterbuck E, Yu LM, Bowman J, Bateman EA, Diggle L, et al. A randomized study comparing combined pneumococcal conjugate and polysaccharide vaccination schedules in adults. Clin Infect Dis 2011;52:73642.

71. Jackson LA, Janoff EN. Pneumococcal vaccination of elderly adults: new paradigms for protection. Clin Infect Dis 2008;47:1328-38.

72. Pilishvili T, Lexau C, Farley MM, Hadler J, Harrison LH, Bennett NM, et al. Sustained reductions in invasive pneumococcal disease in the era of conjugate vaccine. J Infect Dis 2010;201:32-41

73. Moberley SA, Holden J, Tatham DP, Andrews RM. Vaccines for preventing pneumococcal infection in adults. Cochrane Database Syst Rev 2008;(1):CD000422

74. Huss A, Scott P, Stuck AE, Trotter C, Egger M. Efficacy of pneumococcal vaccination in adults: a meta-analysis. CMAJ 2009;180:48-58.

75. Törling J, Hedlund J, Konradsen HB, Ortqvist A. Revaccination with the 23-valent pneumococcal polysaccharide vaccine in middle-aged and elderly persons previously treated for pneumonia. Vaccine 2003;22:96-103.

76. Musher DM, Sampath R, Rodriguez-Barradas MC. The potential role for protein-conjugate pneumococcal vaccine in adults: what is the supporting evidence? Clin Infect Dis 2011;52:633-40.

77. Bocchi EA, Marcondes-Braga FG, Ayub-Ferreira SM, Rohde LE, Oliveira WA, Almeida DR, et al. Sociedade Brasileira de Cardiologia. III Diretriz brasileira de insuficiência cardíaca crônica. Arq Bras Cardiol 2009;92(6 supl 1):1-71.

78. Jessup M, Abraham WT, Casey DE, Feldman AM, Francis GS, Ganiats TG, et al. 2009 Focused Update: ACCF/AHA guidelines for the diagnosis and management of heart failure in adults. Circulation 2009;119:1977-2016.
79. Dickstein K, Cohen-Solal A, Filippatos G, McMurray JJ, Ponikowski P, PooleWilson PA, et al. ESC guidelines for the diagnosis and treatment of acute and chronic heart failure 2008. Eur Heart J 2008;29:2388-442.

80. Smeeth L, Thomas SL, Hall AJ, Hubbard R, Farrington P, Vallance P. Risk of myocardial infarction and stroke after acute infection or vaccination. $\mathrm{N}$ Engl J Med 2004;351:2611-8.

81. Spodick DH, Flessas AP, Johnson MM. Association of acute respiratory symptoms with onset of acute myocardial infarction: prospective investigation of 150 consecutive patients and matched control patients. Am J Cardiol 1984;53:481-2

82. Hung IF, Leung AY, Chu DW, Leung D, Cheung T, Chan CK, et al. Prevention of acute myocardialinfarction and stroke among elderly persons by dual pneumococcal and influenza vaccination: a prospective cohort study. Clin Infect Dis 2010;51:1007-16.

83. Walters JA, Smith S, Poole P, Granger RH, Wood-Baker R. Injectable vaccines for preventing pneumococcal infection in patients with chronic obstructive pulmonary disease. Cochrane Database Syst Rev 2010;(11):CD001390.

84. Chang CC, Singleton RJ, Morris PS, Chang AB. Pneumococcal vaccines for children and adults with bronchiectasis. Cochrane Database Syst Rev 2009;(2):CD006316.

85. Jung JA, Kita H, Dhillon R, Jacobson RM, Nahm MH, Park M, et al. Influence of asthma status on serotype-specific pneumococcal antibody levels. Postgrad Med 2010;122:116-24.

86. Wongsurakiat P, Maranetra KN, Gulprasutdilog P, Aksornint M, Srilum W, Ruengjam C, et al. Adverse effects associated with influenza vaccination in patients with COPD: a randomized controlled study. Respirology 2004;9:550-

87. Vu T, Farish S, Jenkins M, Kelly H. A meta-analysis of effectiveness of influenza vaccine in persons aged 65 years and over living in the community. Vaccine 2002;20:1831-6.

88. Mullooly JP, Bennett MD, Hornbrook MC, Barker WH, Williams WW, Patriarca PA, et al. Influenza vaccination programs for elderly persons: costeffectiveness in a health maintenance organization. Ann Intern Med 1994;121:947-52.

89. Schembri S, Morant S, Winter JH, MacDonald TM. Influenza but not pneumococcal vaccination protects against allcause mortality in patients with COPD. Thorax 2009;64:567-72.

90. Nichol KL. The additive benefits of influenza and pneumococcal vaccinations during influenza seasons among elderly persons with chronic lung disease. Vaccine 1999;17(Suppl 1):S91-3.

91. Nichol KL, Baken L, Wuorenma J, Nelson A. The health and economic benefits associated with pneumococcal vaccination of elderly persons with chronic lung disease. Arch Intern Med 1999;159:2437-42.

92. Furumoto A, Ohkusa Y, Chen M, Kawakami K, Masaki H, Sueyasu Y, et al. Additive effect of pneumococcal vaccine and influenza vaccine on acute exacerbation in patients with chronic lung disease. Vaccine 2008;26:4284

93. Dear K, Holden J, Andrews R, Tatham D. Vaccines for preventing pneumococcal infection in adults. Cochrane Database Syst Rev 2003;(4):CD000422.

94. Halasa NB, Shankar SM, Talbot TR, Arbogast PG, Mitchel EF, Wang WC, et al. Incidence of invasive pneumococcal disease among individuals with sickle cell disease before and after the introduction of the pneumococcal conjugate vaccine. Clin Infect Dis 2007;44:1428-33.

95. Fuentes-Ferrer ME, Cano-Escudero S, Mato-Chaín G, Mariano-Lázaro A Fereres-Castiel J. Vaccination coverage against Streptococcus pneumoniae in splenectomized patients in a fourth-level hospital (1999-2004). Enferm Infecc Microbiol Clin 2008;26:194-8.

96. Stanford E, Print F, Falconer M, Lamden K, Ghebrehewet S, Phin N, et al. Immune response to pneumococcal conjugate vaccination in asplenic individuals. Hum Vaccin 2009;5:85-91.

97. Eigenberger K, Sillaber C, Greitbauer M, Herkner H, Wolf H, Graninger W, et al. Antibody responses to pneumococcal and hemophilus vaccinations in splenectomized patients with hematological malignancies or trauma. Wien Klin Wochenschr 2007;119:228-34

98. Pearson WS, Dube SR, Ford ES, Mokdad AH. Influenza and pneumococcal vaccination rates among smokers: data from the 2006 Behavioral Risk Factor Surveillance System. Prev Med 2009;48:180-3.

99. Pedersen RH, Lohse N, Østergaard L, Søgaard OS. The effectiveness of pneumococcal polysaccharide vaccination in HIV-infected adults: a systematic review. HIV Med 2011:12:323-33. 
100. Peñaranda M, Payeras A, Cambra A, Mila J, Riera M; Majorcan Pneumococcal Study Group. Conjugate and polysaccharide pneumococcal vaccines do not improve initial response of the polysaccharide vaccine in HIV-infected adults. AIDS 2010;24:1226-8.

101. McMahon BJ, Parkinson AJ, Rudolph K, Davidson M, Grabman J. Sepsis due to Streptococcus pneumoniae in a patient with alcoholism who received pneumococcal vaccine. Clin Infect Dis 1999;28:1162-3.
102. Hanna JN, Wenck DJ, Murphy DN. Three fatal pneumococcal polysaccharide vaccine failures. Med J Aust 2000;173:305-7.

103. Shurtleff DB, Loeser JD, Avellino AM, Duguay S, Englund JA, Marcuse EK, et al. Haemophilus influenzae and Streptococcus pneumoniae infections in children with cerebrospinal fluid shunts. Pediatr Neurosurg 2009;45:27680. 